\title{
PAPR Reduction for Improved Efficiency of OFDM Modulation for Next Generation Communication Systems
}

\author{
Shatrughna Prasad Yadav ${ }^{1}$, Subhash Chandra Bera ${ }^{2}$ \\ ${ }^{1}$ Electrical and Electronics Engineering Department, Indus University, Ahmedabad, Gujarat, India \\ ${ }^{2}$ Satcom \& Navigation Systems Engineering Division, Space Applications Centre, Indian Space Research Organization,
} Ahmedabad, India

\section{Article Info}

Article history:

Received Apr 15, 2016

Revised Jul 1, 2016

Accepted Jul 18, 2016

\section{Keyword:}

Clipping and Filtering

DFT Spread

OFDM

PAPR

Partial Transmit Sequence

Selective Mapping Method

\begin{abstract}
Highly linear power amplifiers are required for transferring large amount of data for future communication. Orthogonal frequency division multiplexing (OFDM) provides high data rate transmission capability with robustness to radio channel impairments. It has been widely accepted for future communication for different services. But, it suffers from high value of peakto-average power ratio (PAPR). High value of PAPR drives high power amplifiers in saturation and causes it to operate in the nonlinear region. In this paper, comparative study of four different PAPR reduction techniques: clipping and filtering (CF), selective mapping method (SLM), partial transmit sequence (PTS) and DFT- spread technique have been done. Mathematical modeling and Matlab simulations have been performed to arrive at the results with 4 QAM modulation format and 1024 number of sub carriers. At $0.01 \%$ of complementary cumulative distribution function (CCDF) significant reduction of 11.3, 3.5, 3.4 and $1.0 \mathrm{~dB}$ have been obtained with DFT- spread, SLM, PTS and CF techniques respectively.
\end{abstract}

Copyright (c) 2016 Institute of Advanced Engineering and Science. All rights reserved.

\section{Corresponding Author:}

Shatrughna Prasad Yadav,

Electrical and Electronics Engineering Department,

Indus University,

Ahmedabad, Gujarat, India.

Email: spyadav68@gmail.com

\section{INTRODUCTION}

The future generation communication requires high data rate. But dealing with the high data rate in an unpredictable wireless channel is a difficult task. In order to exchange larger amount of information highly linear power amplifiers are required. With the application of orthogonal frequency division multiplexing (OFDM) power amplifier nonlinearities becomes more vulnerable owing to their high peak to average power ratio (PAPR) caused due to large fluctuations in their signal envelope. OFDM is desirable because of several advantages associated with it, such as, tolerance to inter-symbol interference, good spectral efficiency, best performance of frequency selective fading in multipath environment, robustness to channel impairments etc. OFDM is efficiently used to combat the unpredictability of wireless channel and provide high data rate communications [1]. When compared with traditional communication systems, it has several advantages over it. It turns the frequency-selective fading channel into a flat fading channel and hence uses simple receiver. It is spectrally efficient and is ideal for multimedia communication systems. On the other hand, it is sensitive to timing and frequency synchronization errors and has high value of PAPR [2].

OFDM systems has many applications and are widely used in high-bit-rate digital subscriber lines (HDSL), digital audio broadcasting (DAB), digital video broadcasting (DVB) along with high-definition television (HDTV), terrestrial broadcasting, etc. It is considered as a better candidate for the future generation communication systems [3]. In the OFDM transmitter the digitally mapped 4-QAM signal is 
divided into $\mathrm{N}$ number of subcarriers with the help of serial to parallel $(\mathrm{S} / \mathrm{P})$ converter. Then each subcarrier is multiplied with a complex signal $\mathrm{e}^{\mathrm{j} \Delta \omega \mathrm{nt}}$ and added together to get the OFDM signal. This is equivalent to inverse discrete Fourier transform (IDFT) operation and is implemented through inverse fast Fourier transform (IFFT) [4]. The time-domain signal, $r_{n}$ is given as in equation (1).

$$
\mathrm{r}_{\mathrm{n}}=\left\{\begin{array}{l}
\frac{1}{\mathrm{Tu}} \sum_{\mathrm{n}=0}^{\mathrm{N}-1} \mathrm{X}_{\mathrm{n}}[\mathrm{n}] \mathrm{e}^{\mathrm{j} \Delta \omega \mathrm{nt}} \begin{array}{r}
0 \leq \mathrm{t} \leq \mathrm{Tu} \\
\text { otherwise }
\end{array}
\end{array}\right.
$$

After frequency- to time-domain conversion, the signal is summed up, and the cyclic prefix is added as given in equation (2).

$$
\mathrm{s}_{\mathrm{n}}=\left\{\begin{array}{lc}
\mathrm{r}_{\mathrm{n}}(\mathrm{t}+\mathrm{Tu}-\mathrm{Tg}), & 0 \leq \mathrm{t} \leq \mathrm{Tg} \\
\mathrm{r}_{\mathrm{n}}(\mathrm{t}-\mathrm{Tg}), & \mathrm{Tg}<t<T s \\
0 & \text { otherwise }
\end{array}\right.
$$

Where, $T_{u}$ is the useful symbol period, $T_{g}$ is cyclic prefix duration (guard interval) and $T_{s}=T_{u}+T_{g}$ is the total OFDM symbol duration. The transmitted baseband signal is formed by linking together all OFDM symbols in time domain as in equation (3).

$$
\mathrm{s}(\mathrm{t})=\sum_{\mathrm{n}=0}^{\mathrm{N}-1} \mathrm{~s}_{\mathrm{n}}\left(\mathrm{t}-\mathrm{sT}_{\mathrm{s}}\right)
$$

Cyclic prefix is added to reduce effect of inter symbol interference and inter carrier interference and to maintain orthogonality between the two signals. Normally, some part of the front portion of the signal is copied and pasted in the empty space usually provided for the guard band in the normal communication systems. This signal is finally up converted to a carrier frequency through bandpass modulation and transmitted as given in equation (4). Where, $u(t)$ is the transmitted $R F$ signal and $f_{c}$ is the RF carrier frequency.

$$
u(t)=\operatorname{Re}\left\{s(t) e^{j 2 \pi f_{c} t}\right\}
$$

Matlab simulation has been performed at $2 \mathrm{GHz}$ carrier frequency with 1024 number of subcarriers (N), $5.12 \mu \mathrm{s}$ of useful symbol period (Tu), $0.16 \mu$ s of guard interval (cyclic prefix) and $5.28 \mu$ s of total OFDM symbol period [5]. 4-QAM baseband modulation with IFFT of length 2048 (2L) has been considered. To achieve over sampling zeroes are padded to the signal.

\section{PEAK TO AVERAGE POWER RATIO OF THE OFDM SIGNAL}

PAPR is a measure used to quantify the fluctuations in the envelope of multicarrier signals [6]. For a given sample $\left\{\mathrm{x}_{\mathrm{m}}\right\}$ the average power and peak power for an OFDM system is given by equation (5) and (6) respectively.

$$
\begin{aligned}
& \mathrm{P}_{\mathrm{av}}=\frac{1}{\mathrm{~F}_{\mathrm{s}}} \sum_{\mathrm{n}=0}^{\mathrm{F}_{\mathrm{s}}-1} \mathrm{x}_{\mathrm{m}}^{2} \\
& \mathrm{P}_{\text {peak }}=\max _{\mathrm{m}}\left\{\mathrm{x}_{\mathrm{m}}^{2}\right\}
\end{aligned}
$$

Peak - to - Average Power ratio (PAPR) in OFDM system is defined as the ratio of maximum (peak) power to average power of the complex passband discrete time signal as given by equation (7).

$$
\operatorname{PAPR}=\frac{\mathrm{P}_{\text {peak }}}{\mathrm{P}_{\mathrm{av}}}
$$

It is also expressed in terms of crest factor (CF) given by equation (8).

$$
\mathrm{CF}=\sqrt{\mathrm{PAPR}}
$$

For a large number of subcarriers, the baseband OFDM signal can be approximated by a complex Gaussian distribution. Cumulative distribution function (CDF) of the amplitude of the samples is used to measure percentage of the samples which are affected by the clipping operation [7]. Cumulative distribution 
function (CDF) of $z_{\max }$ is given as in equation (9).

$$
\mathrm{Fz}_{\max }(\mathrm{z})=\mathrm{P}\left(\mathrm{z}_{\max }<z\right)=\mathrm{P}\left(\mathrm{z}_{0}<z\right) \cdot \mathrm{P}\left(\mathrm{z}_{1}<z\right) \ldots \ldots \cdot \mathrm{P}\left(\mathrm{z}_{\mathrm{N}-1}<z\right)=\left(1-\mathrm{e}^{-\mathrm{z}^{2}}\right)^{\mathrm{N}}(9)
$$

Where,

$$
\mathrm{P}\left(\mathrm{z}_{\mathrm{N}}<z\right)=\int_{0}^{\mathrm{z}} \mathrm{fz} \text { ( }(\mathrm{u}) \mathrm{du}, \mathrm{n}=0,1,2, \ldots \ldots \mathrm{N}-1
$$

Complementary cumulative distribution function (CCDF) is used to find out the probability that the PAPR (crest factor) exceeds a particular value as given in equation (11).

$$
\tilde{\mathrm{F}} \mathrm{z}_{\max }(\mathrm{z})=\mathrm{P}\left(\mathrm{z}_{\max }>\mathrm{z}\right)=1-\mathrm{P}\left(\mathrm{z}_{\max } \leq \mathrm{z}\right)=1-\mathrm{Fz}_{\max }(\mathrm{z})=1-\left(1-\mathrm{e}^{-\mathrm{z}^{2}}\right)^{\mathrm{N}}
$$

PAPR value of the OFDM system is plotted in Figure 1 and 2 for QPSK and 4 QAM modulation respectively for different number of subcarriers. At $0.01 \%$ of CCDF, PAPR values for QPSK modulation are $10.5,10.7,10.9,11.2$ and $11.4 \mathrm{~dB}$ for $\mathrm{N}=64,128,256,512$ and 1024 respectively. Similarly for QAM modulation these values are $11.5,11.7,12.0,12.2$, and $12.5 \mathrm{~dB}$ respectively. It is evident from the figure that value of PAPR increases with increase in number of subcarriers and 4-QAM modulation has approximately $1.0 \mathrm{~dB}$ higher PAPR than that of QPSK modulation format.

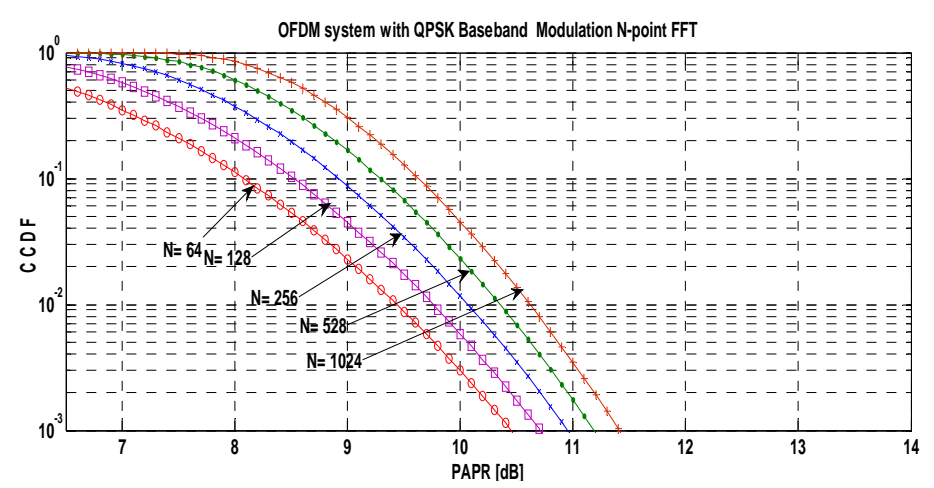

Figure 1. PAPR of the original OFDM system with QPSK baseband modulation

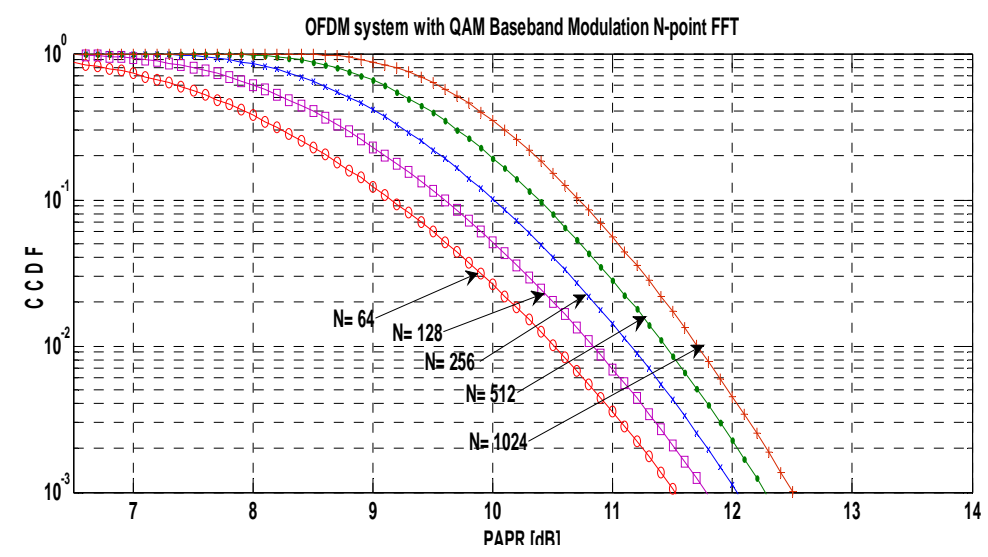

Figure 2. PAPR of the original OFDM system with 4 QAM baseband modulation

\section{PAPR REDUCTION TECHNIQUES}

There are different techniques used for PAPR reduction. In this paper we have investigated following four techniques: clipping and filtering, selective mapping method (SLM), partial transmit sequence (PTS) and 
discrete Fourier transform (DFT) spread technique. Each reduction technique is having certain advantages and disadvantages associated with it over another technique. Application of particular technique depends upon the value of PAPR desired and computational complexity involved. It can be observed from the results obtained that the DFT spread technique gives lowest PAPR value but its implementation is difficult. On the other hand, clipping and filtering method is simplest from application point of view but gives distortions and spectral regrowth.

\subsection{Clipping and Filtering Method}

PAPR can be reduced by clipping the peak amplitude of the transmitted signal and passing it through a low pass filter [8]. In case of over sampled signal band pass filter is required to reduce the out of band radiation. But for the band limited signal clipped at Nyquist sampling rate all the distortions lies within the band, hence a low pass filter is sufficient [9],[10]. But the low pass filter used after clipping operation moderately enlarges the PAPR. PAPR can be also reduced by clipping and frequency domain filtering as shown in Figure 3. To reduce peak regrowth caused by filtering recursive/ iterative clipping and filtering techniques are also used [11].

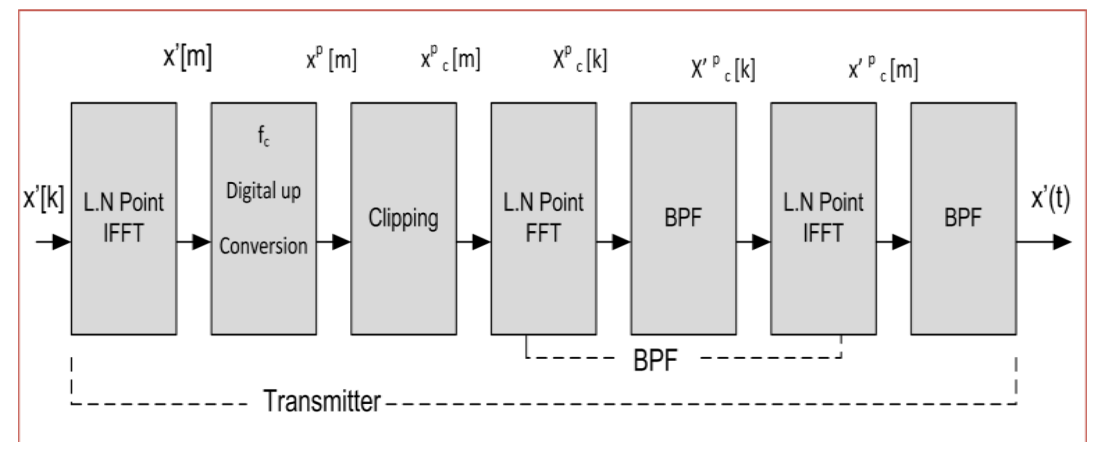

Figure 3. Clipping and filtering with over sampling factor

The L-times oversampled discrete-time signal $\mathrm{x}^{\prime}[\mathrm{m}]$ is generated from the IFFT operation. Then it is modulated with carrier frequency $\mathrm{f}_{c}$ to yield a passband signal $\mathrm{x}^{\mathrm{p}}[\mathrm{m}]$, where $\mathrm{x}_{\mathrm{c}}^{\mathrm{P}}[\mathrm{m}]$ denote the clipped version of signal $\mathrm{x}^{\mathrm{p}}[\mathrm{m}]$ and is expressed as given in equation (12).

$$
\mathrm{x}_{\mathrm{c}}^{\mathrm{P}}[\mathrm{m}]=\left\{\begin{array}{cc}
-\mathrm{A} & \mathrm{x}^{\mathrm{p}}[\mathrm{m}] \leq-\mathrm{A} \\
\mathrm{x}^{\mathrm{p}}[\mathrm{m}] & \left|\mathrm{x}^{\mathrm{p}}[\mathrm{m}]\right|<A \\
\mathrm{~A} & \mathrm{x}^{\mathrm{p}}[\mathrm{m}] \geq \mathrm{A}
\end{array}\right.
$$

PAPR also depends upon clipping ratio (CR) which is defined as the clipping level normalized by the RMS value $\sigma$ of OFDM signal given as in equation (13).

$$
\mathrm{CR}=\frac{\mathrm{A}}{\sigma}
$$

\subsubsection{PAPR of Clipped and Filtered signal}

When bandpass OFDM signal is passed through a clipper circuit its PAPR value decreases significantly. Figure 4 shows the CCDFs of PAPR value for the clipped OFDM signals for 1024 number of sub carriers at $2 \mathrm{GHz}$ of carrier frequency with 4-QAM modulation format. It can be noted from the figure that at $0.01 \%$ of CCDF with clipping ratio of $0.8,1.0,1.2,1.4$ and 1.6 the PAPR values are 4.6, 5.0, 5.5, 5.9 and $6.5 \mathrm{~dB}$ respectively. From the figure it is observed that the PAPR value of the OFDM signal decreases significantly after clipping. It has also been observed that smaller the clipping ratio (CR) greater is the PAPR reduction effect [12]. But this decrease in PAPR is at the cost of increase in the bit error rate and spectral regrowth [13].

Similarly Figure 5 shows PAPR value of clipped OFDM signal when it is allowed to pass through a filter cicuit. For the same parameters as mentioned above the PAPR values are 10.7, 11.0, 11.2, 11.4 and 11.7 $\mathrm{dB}$ with clipping ratio of $0.8,1.0,1.2,1.4$ and 1.6 respectively. 


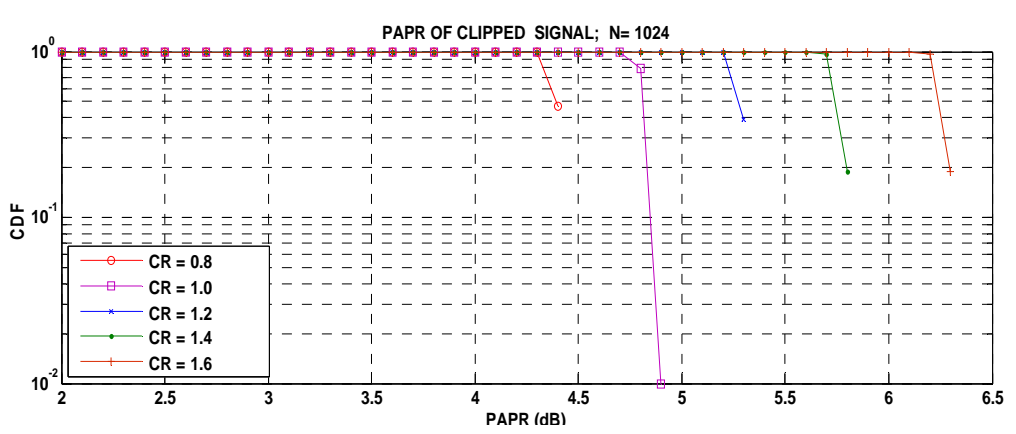

Figure 4. PAPR of clipped signals for $\mathrm{N}=1024$

When it is compared with PAPR value of clipped signal, its value has increased by approximately $2.0 \mathrm{~dB}$ after filtering procees. But the bit error rate and spectral regrowth has been decraesed significantly [14].

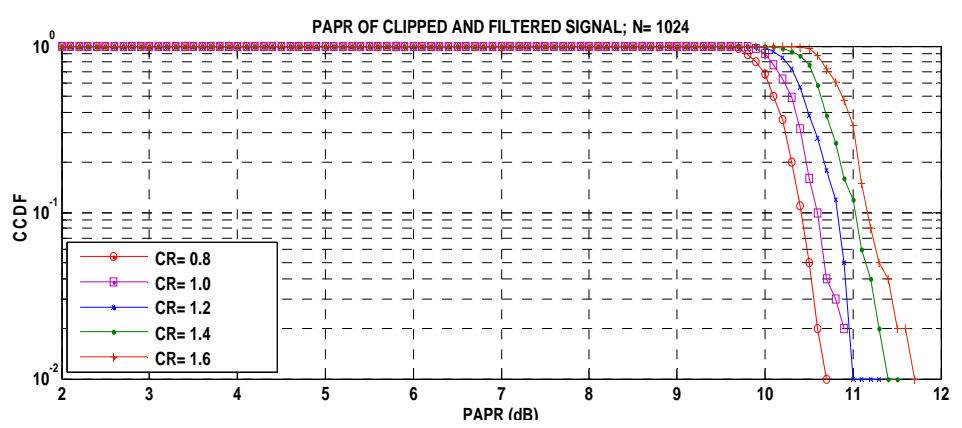

Figure 5. PAPR of clipped and filtered signal for $\mathrm{N}=1024$

\subsubsection{Bit Error Rate Performance of Clipped and Filtered Signal}

Figures 6, 7 and 8 shows the BER performance for unclipped, clipped only and clipped and filtered signal respectively. The BER value for unclipped signal at $10 \mathrm{~dB}$ of signal power is 0.0007 .

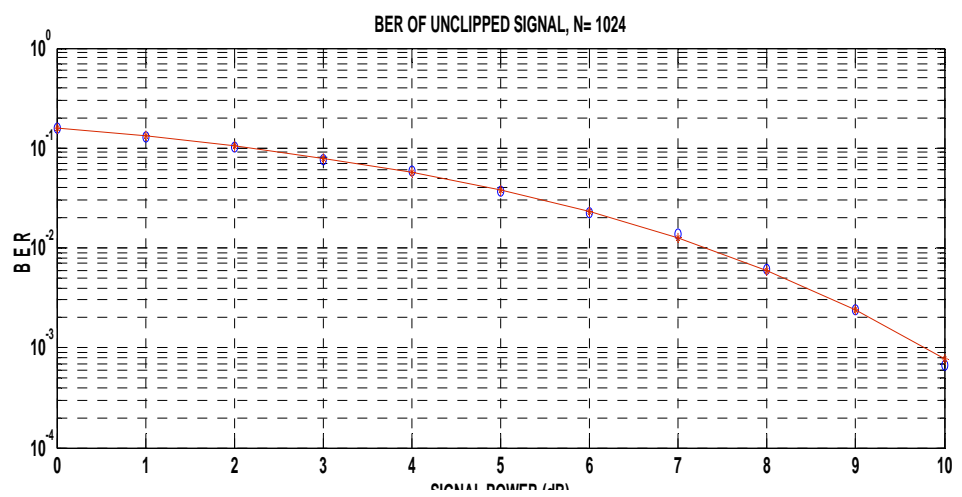

Figure 6. BER Performance of unclipped signal

It can be observed from Figure 7 that BER performance is a function of clipping ratio (CR). For the clipped signal it is observed from the figure that at $10 \mathrm{~dB}$ of signal power and with $\mathrm{CR}$ value of $0.8,1.0,1.2$, 1.4 and 1.6 the BER values are $0.041,0.027,0.019,0.010$ and 0.007 respectively. It can be observed that as the value of clipping ratio decreases BER performance becomes worse. This increase in BER value is due to distortions caused during the process of clipping [15]. 


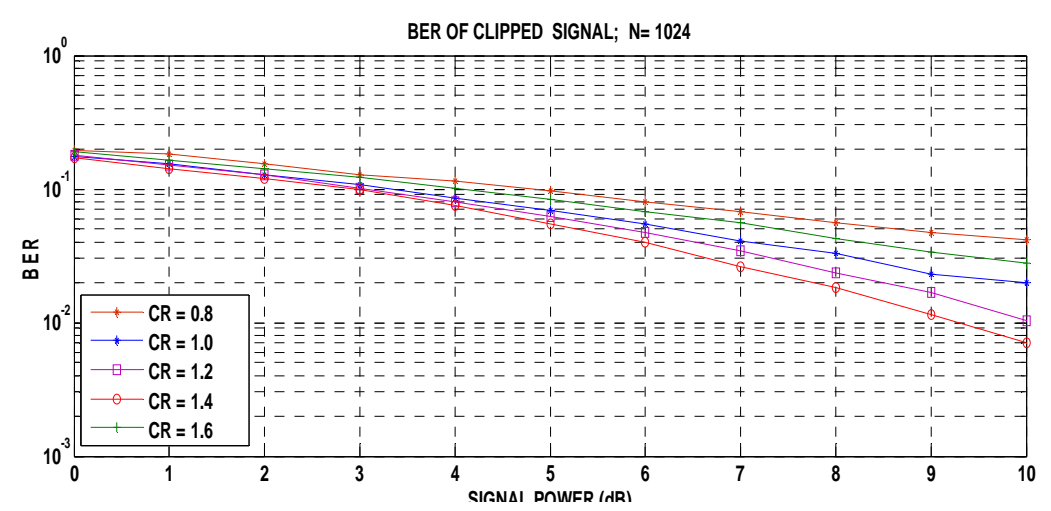

Figure 7. BER Performance of clipped signal for $\mathrm{N}=1024$

When the clipped signal is passed through filter circuit its BER value improves. At $10 \mathrm{~dB}$ of signal power and at CR value of $0.8,1.0,1.2,1.4$ and 1.6 the BER values of clipped and filtered signal are 0.019, $0.013,0.007,0.005$ and 0.003 respectively. The improvement in BER in clipped and filtered signal is approximately 0.014 at $\mathrm{CR}$ value of 1.0 than that of only clipped signal.

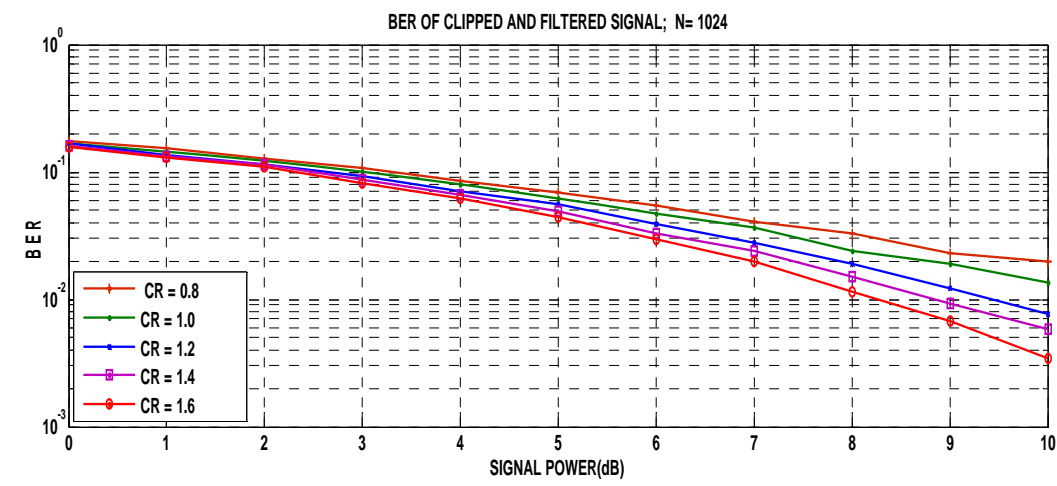

Figure 8. BER Performance with clipped and filtered signal for $\mathrm{N}=1024$

\subsection{Selective Mapping Method}

Selective mapping method (SLM) is one of the important method for reducing PAPR of OFDM system. It has many advantages over other methods, such as: simple in implementation, absence of distortions in the transmitted signal, and significant reduction in PAPR [16]. In this method the original data block is converted into several independent signals. Different phase rotations are applied to parallel baseband modulated signals. The phase rotation which gives minimum PAPR value of the time signal is selected [17]. A large set of data vectors, all representing the same information is generated during this process. The data vector which generates lowest PAPR value is selected for transmission. Side information is transmitted to the receiver having information about these data vectors. This extra information is an overhead to the channel which reduces the overall data rate [18].

Figure 9 shows the block diagram of selective mapping (SLM) technique. Here, the input data block $\mathrm{X}=[\mathrm{X}[0], \mathrm{X}[1], \ldots . \mathrm{X}[\mathrm{N}-1]$ is multiplied with $\mathrm{U}$ different phase sequences as given in equation (14).

$$
\mathrm{P}^{\mathrm{u}}=\left[\mathrm{P}_{0}^{\mathrm{u}}, \mathrm{P}_{1}^{\mathrm{u}}, \ldots \ldots \mathrm{P}_{\mathrm{N}-1}^{\mathrm{u}}\right]^{\mathrm{T}}
$$

Where, $\mathrm{P}_{\mathrm{v}}^{\mathrm{u}}=\mathrm{e}^{\mathrm{j} \varphi_{\mathrm{v}}^{\mathrm{u}}}$ and $\varphi_{\mathrm{v}}^{\mathrm{u}} \in[0,2 \pi]$ for $\mathrm{v}=0,1, \ldots ., \mathrm{N}-1$ and $\mathrm{u}=1,2, \ldots . \mathrm{U}$ which produce a modified data block as in equation (15).

$$
\mathrm{X}^{\mathrm{u}}=\left[\mathrm{X}^{\mathrm{u}}[0], \mathrm{X}^{\mathrm{u}}[1], \ldots \ldots . \mathrm{X}^{\mathrm{u}}[\mathrm{N}-1]\right]^{\mathrm{T}}
$$




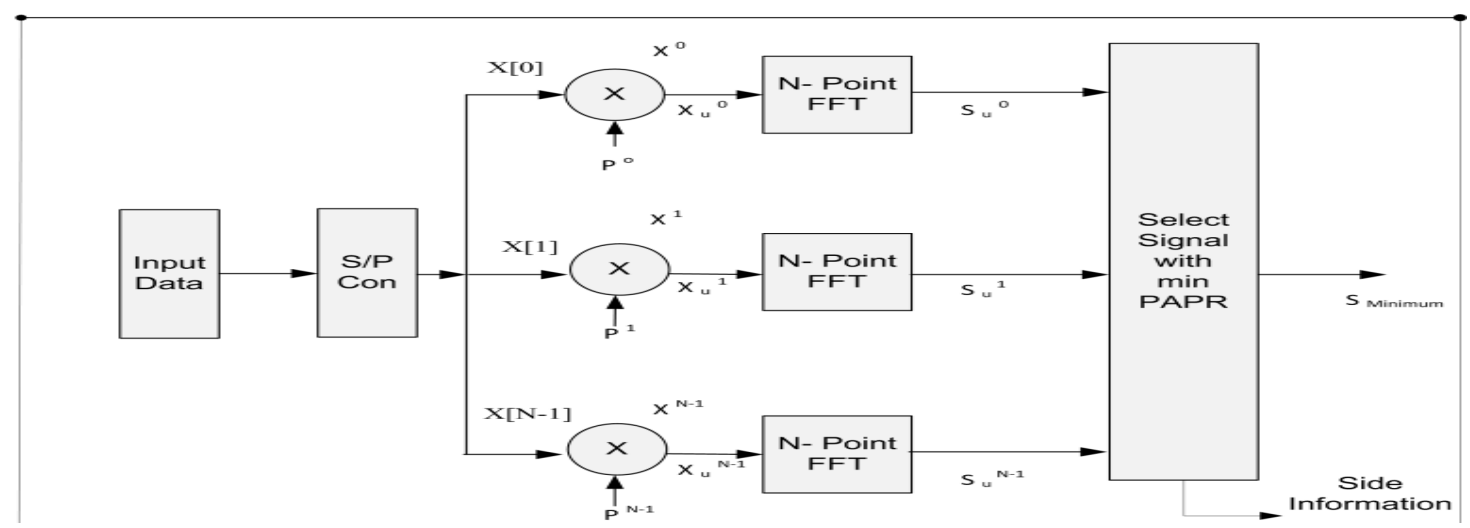

Figure 9. Block diagram of Selected Mapping Method

Among which the one $S_{\min }=S_{u}^{N}$ with the lowest PAPR is selected for transmission as given in equation (16).

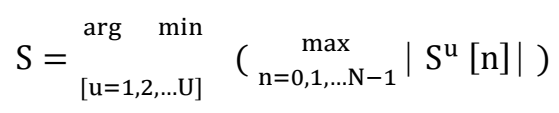

In order to recover the original data block information about the selected phase sequence is transmitted as a side information. Implementation of SLM technique requires U IFFT operations. Furthermore, it requires $\log _{2} \mathrm{U}$ bits of side information for each data block.

\subsubsection{PAPR with Selective Mapping Method}

Matlab simulation has been carried out to calculate the value of PAPR for 1024 number of subcarriers. As shown in Figure 10 it can be observed that at 0.01 percent of CCDF, PAPR values obtained with phase vectors, $\mathrm{U}=16,8,4,2$ and 1 are 8.2, 8.4, 8.9, 9.7 and $10.6 \mathrm{~dB}$ respectively. It is also evident from the figure that PAPR value is lowest for larger number of phase rotations $(U=16)$ which increases with either increase in number of subcarriers or reduction in phase vectors.

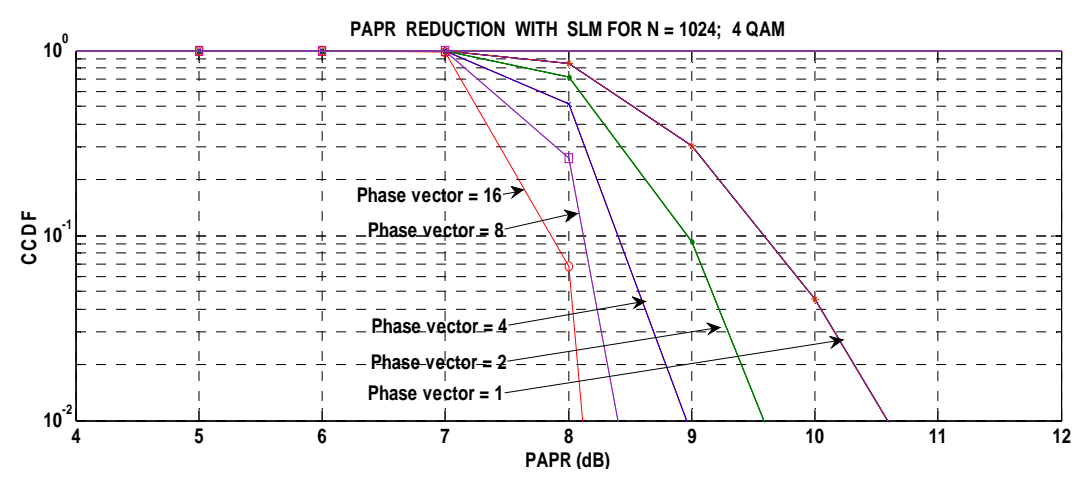

Figure 10. PAPR reduction with SLM with $\mathrm{N}=1024$

\subsection{Partial Transmit Sequence}

The partial transmit sequence (PTS) technique as shown in Figure 11 partitions an input data block of $\mathrm{N}$ symbols into $\mathrm{M}$ disjoint subblocks as follows:

$$
\mathrm{x}=\left[\mathrm{x}_{0}, \mathrm{x}_{1}, \mathrm{x}_{2}, \mathrm{x}_{3}, \ldots \ldots . \mathrm{x}_{\mathrm{v}}\right]^{\mathrm{T}}
$$

Here, $x_{i}$ are the subblocks that are consecutively located and are of equal size. Unlike the SLM technique in which scrambling is applied to all subcarriers in this technique scrambling is applied to each subblock [19]. 


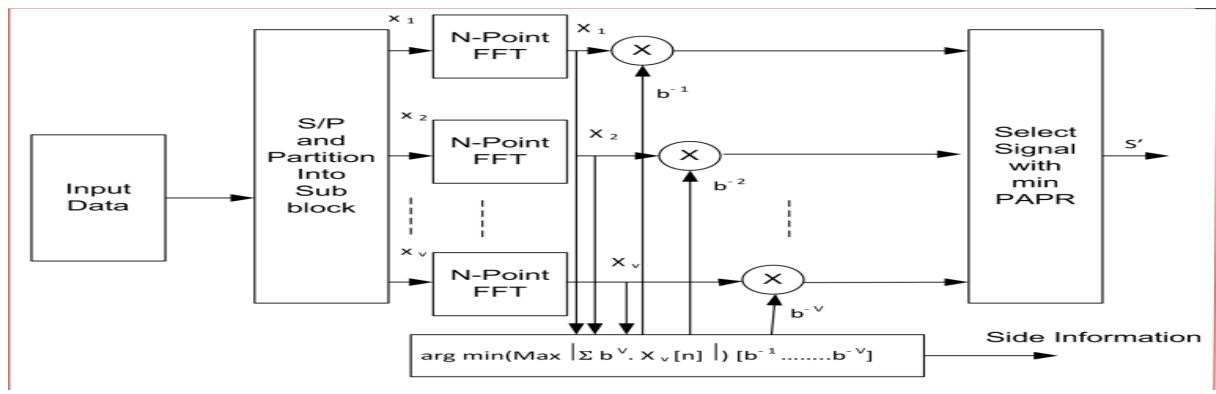

Figure 11. Block diagram of PTS for PAPR reduction

Then each partitioned subblock is multiplied by a corresponding complex phase factor $\mathrm{b}^{\mathrm{n}}=\mathrm{e}^{\mathrm{j} b \mathrm{n}}$ where, $\mathrm{n}=1,2, \ldots \mathrm{N}$. Subsequently taking its IFFT to yield

$$
\mathrm{x}=\operatorname{IFFT}\left\{\sum_{\mathrm{n}=1}^{\mathrm{N}} \mathrm{b}^{\mathrm{n}} \mathrm{X}^{\mathrm{n}}\right\} \quad=\sum_{\mathrm{v}=1}^{\mathrm{v}} \mathrm{b}^{\mathrm{n}} \cdot \operatorname{IFFT}\left\{\mathrm{X}^{\mathrm{n}}\right\} \quad=\sum_{\mathrm{n}=1}^{\mathrm{N}} \mathrm{b}^{\mathrm{n}} \mathrm{X}^{\mathrm{n}}
$$

Where $\left\{\mathrm{x}^{\mathrm{n}}\right\}$ is referred to as partial transmit sequence (PTS) and the phase vector is chosen so that the PAPR can be minimized. The corresponding time-domain signal with the lowest PAPR vector can be expressed as in equation (19).

$$
\mathrm{s}^{\prime}=\sum_{\mathrm{v}=1}^{\mathrm{v}} \mathrm{b}^{-\mathrm{n}} \mathrm{x}^{\mathrm{n}}
$$

Selection of the phase factors $\left\{b^{\mathrm{m}}\right\}_{\mathrm{N}-1}^{\mathrm{N}}$ is limited to a set of elements to reduce the search complexity. The PTS technique requires M IFFT operations for each data block and $\left[\log _{2} \mathrm{X}^{\mathrm{n}}\right]$ bits of side information [20]. The PAPR performance of the PTS technique depend upon many factors, such as the number of subblocks, number of allowed phase factors, and subblock partitioning. Subblock partitioning is a method of dividing the subbands into multiple of subbands which are disjoint. There are three different types of the subblock partitioning schemes: adjacent, interleaved and pseudo-random. The pseudo-random partitioning scheme has been known to provide the best performance and has been considered for the simulation purpose [21]. In the interleaved method, every subband signals spaced at the interval of $\mathrm{N}$ apart is allocated the same subband. In the adjacent method in which N/M successive subbands are given the same subblock sequentially. On the other hand, in the pseudo - random method each subband signal is assigned into any one of the subblocks randomly. In PTS, each subblock is to be modulated by independent IFFT. Due to reduction in number of subblocks the computational complexity of PTS technique is comparatively less than that of SLM method.

\subsubsection{PAPR with Partial Transmit Sequence}

The Matlab simulation using pseudo - random method of block partitioning has been carried out. 4QAM signal constellation has been taken into consideration with 8000 blocks. Figure 12 shows the PAPR values at 0.01 percent of CCDF for 1024 number of sub carriers as 8.3, 8.6, 9.1, 9.8 and $10.6 \mathrm{~dB}$ for the number of sub blocks, $\mathrm{V}=16,8,4,2$ and 1 respectively. From figure it is clear that PAPR value is lowest for large number of sub blocks $(\mathrm{V}=16)$. As in the previous methods it increases with either increase in the number of subcarriers or reduction in the number of sub blocks.

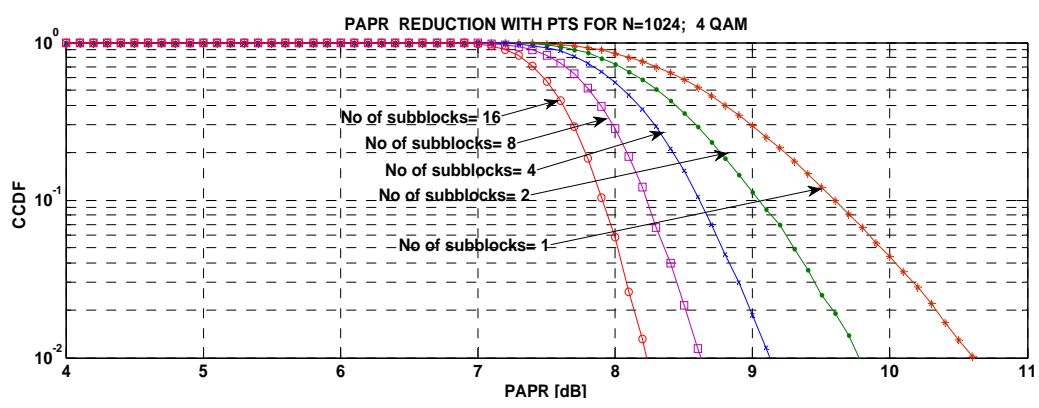

Figure 12. PAPR reduction with PTS for $\mathrm{N}=1024$

PAPR Reduction for Improved Efficiency of OFDM Modulation for Next .... (Shatrughna Prasad Yadav) 


\subsection{DFT Spread Technique}

Transmitter of a DFT spread system consists of a serial to parallel convertor, DFT spreading, IDFT despreading, parallel to serial converter, addition of cyclic prefix, digital to analog converter and RF modulation for converting baseband signal into passband signal before transmitting it through the channel [22]. If size of DFT is same as that of IDFT, the OFDMA system becomes equivalent to the single carrier FDMA (SC-FDMA) system because the DFT and IDFT operations virtually cancel each other. Then the transmit signal will have the same PAPR as in a single-carrier system [23]. The equivalence of OFDMA system with DFT-spread technique is shown in Figure 13.

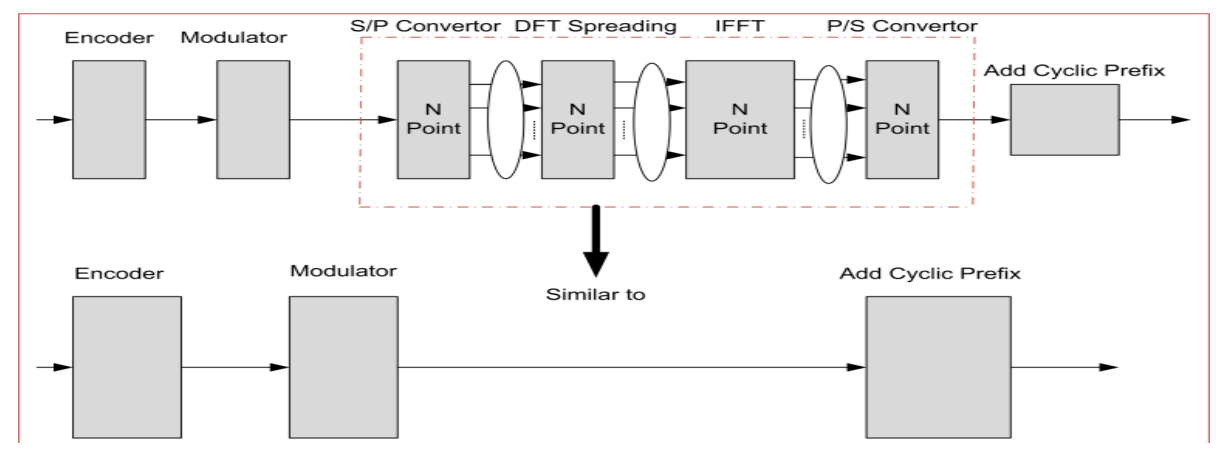

Figure 13. Equivalence of OFDMA systems with DFT-spread

When we consider a conventional OFDMA system, subcarriers are partitioned and assigned to multiple mobile users. But in this technique, each user uses a subset of subcarriers to transmit its own data. The subcarriers which are not used for the data transmission are filled with zeros [24]. Here, the number of subcarriers allocated to each user is assumed to be M. In the DFT-spreading technique, M-point DFT is used for spreading, and the output of DFT is assigned to the subcarriers of IDFT. The effect of PAPR reduction depends on the way of assigning the subcarriers to each terminal. Two different approaches of assigning subcarriers are used among users, DFDMA (Distributed FDMA) and LFDMA (Localized FDMA). In DFDMA, M DFT outputs are distributed over the entire band of total N subcarriers with zeros filled in N-M unused subcarriers. But in the LFDMA, DFT outputs are allocated to $\mathrm{M}$ consecutive subcarriers in $\mathrm{N}$ subcarriers and remaining are filled with zeros. If distribution of DFT outputs in DFDMA is done uniformly with equal distance then it is referred to as interleaved FDMA (IFDMA) [25]. Input data s[m] is DFT-spread to generate $\mathrm{S}(\mathrm{k})$ signals in frequency domain as given in equation (20).

$$
\mathrm{S}(\mathrm{k})=\sum_{\mathrm{k}=0}^{\mathrm{M}-1} \mathrm{~s}[\mathrm{~m}] \mathrm{e}^{-\mathrm{j} 2 \Pi n \mathrm{n} / \mathrm{N}}
$$

These are allocated as depicted in equation (21).

$$
\mathrm{S}^{\prime}(k)=\left\{\begin{array}{cc}
\mathrm{S}\left[\frac{\mathrm{k}}{\mathrm{x}}\right], & \mathrm{k}=\mathrm{X} . \mathrm{m} ; \mathrm{m}=0,1,2,3 \ldots \ldots, \mathrm{M}-1 \\
0, & \text { otherwise }
\end{array}\right.
$$

The IFFT output sequence $\mathrm{s}(\mathrm{n})$ with $\mathrm{n}=\mathrm{M} . \mathrm{x}+\mathrm{m}$ for $\mathrm{x}=0,1,2, \ldots \ldots \ldots, \mathrm{X}-1$ and $\mathrm{m}=0,1,2$, ..., M-1 can be expressed as shown in equation (22).

$$
s(n)=\frac{1}{\mathrm{X}} \quad \sum_{m=0}^{\mathrm{M}-1} \mathrm{~s}(\mathrm{~m})
$$

It can be seen from Equations (22) that the time-domain LFDMA signal becomes the 1/X-scaled copies of the input sequence.

\subsubsection{PAPR of DFT Spread technique}

PAPR performances using DFT spread technique is shown in Figure 14 for 1024 number of subcarriers applied to the IFDMA, LFDMA, and OFDMA systems. The PAPR value for IFDMA, LFDMA, and OFDMA are $0.04,6.9$ and $10.6 \mathrm{~dB}$ respectively. 


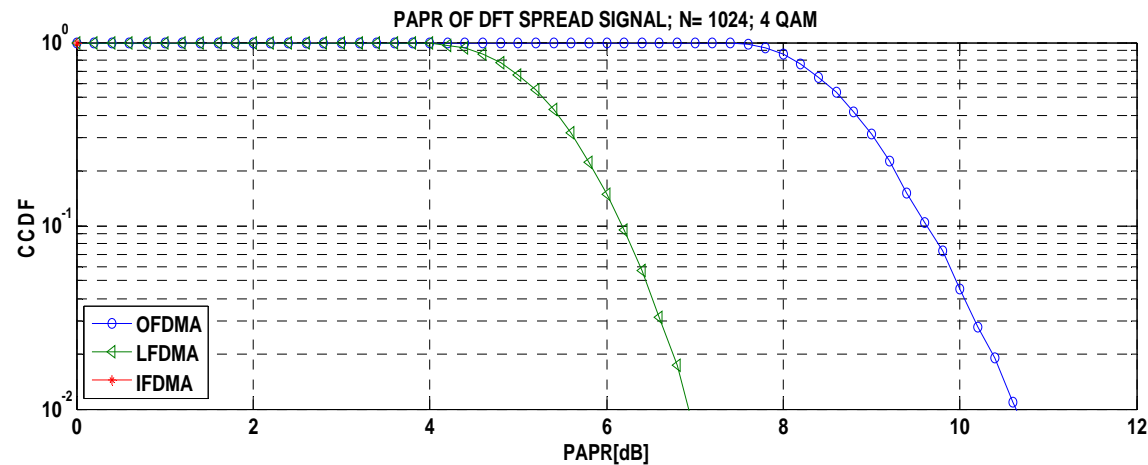

Figure 14. PAPR performances for IFDMA, LFDMA, and OFDMA for N=1024; 4 QAM

It can be observed from Figures 14, 15 and 16 that the PAPR performance of the DFT-spread technique varies with modulation order and subcarrier allocation method.

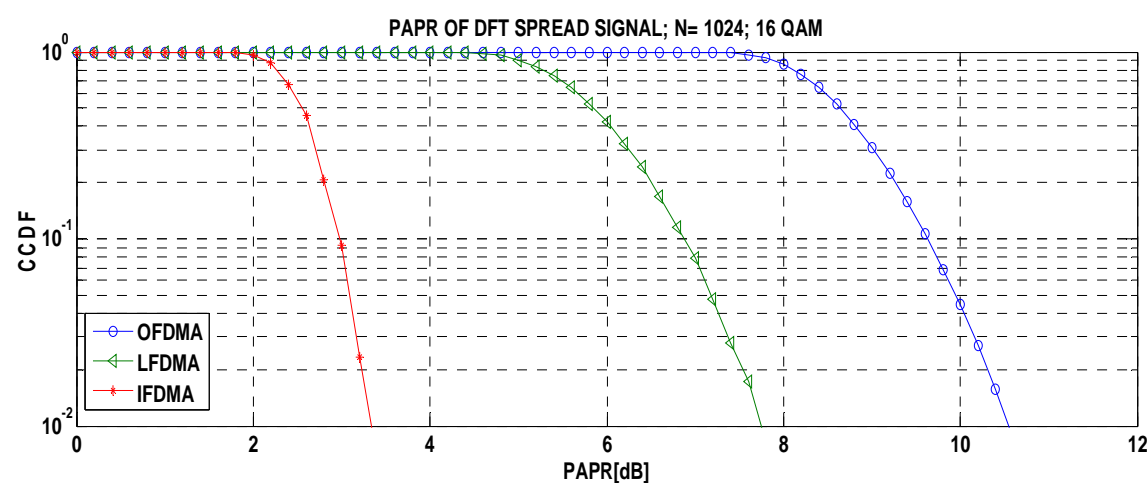

Figure 15. PAPR performances for IFDMA, LFDMA, and OFDMA for N=1024; 16 QAM

For the case of 4-QAM modulated signal at $0.01 \%$ of CCDF the values of PAPRs with IFDMA, LFDMA, and LFDMA are 0.4, 6.9 and $10.6 \mathrm{~dB}$ respectively. But for 16-QAM modulated signal, the values are 3.4, 7.8 and 10.6 dB respectively. Similarly for 64-QAM modulated signal the corresponding values are found to be 4.6, 7.9 and $10.6 \mathrm{~dB}$ respectively.

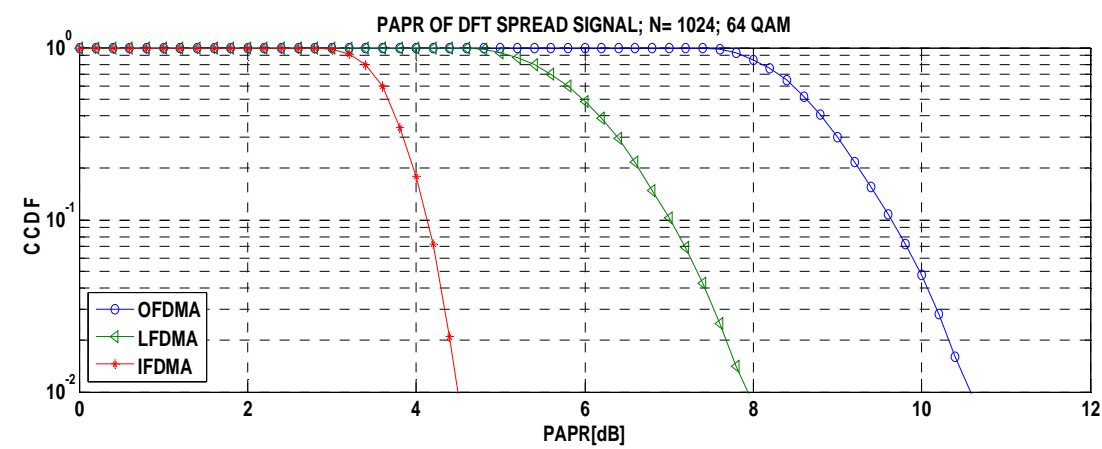

Figure 16. PAPR performances for IFDMA, LFDMA, and OFDMA for N=1024; 64 QAM 


\section{RESULTS AND ANALYSIS}

Comparative performance of all the PAPR reduction techniques discussed above is illustrated in fig. 17 for 4 QAM modulation format with 1024 number of sub carriers. The observed PAPR values at $0.01 \%$ of CCDF with IFDMA technique is $0.4 \mathrm{~dB}$, clipped only at $\mathrm{CR}=0.8$ has $4.6 \mathrm{~dB}$, LFDMA has $6.9 \mathrm{~dB}$, SLM with number of Phase Vector, $\mathrm{V}=16$ has $8.2 \mathrm{~dB}$, PTS with No. of sub blocks $=16$ has $8.3 \mathrm{~dB}$, OFDMA has $10.5 \mathrm{~dB}$, clipped and filtered at $\mathrm{CR}=0.8$ has $10.7 \mathrm{~dB}$ and unclipped signal has PAPR value of $11.7 \mathrm{~dB}$.

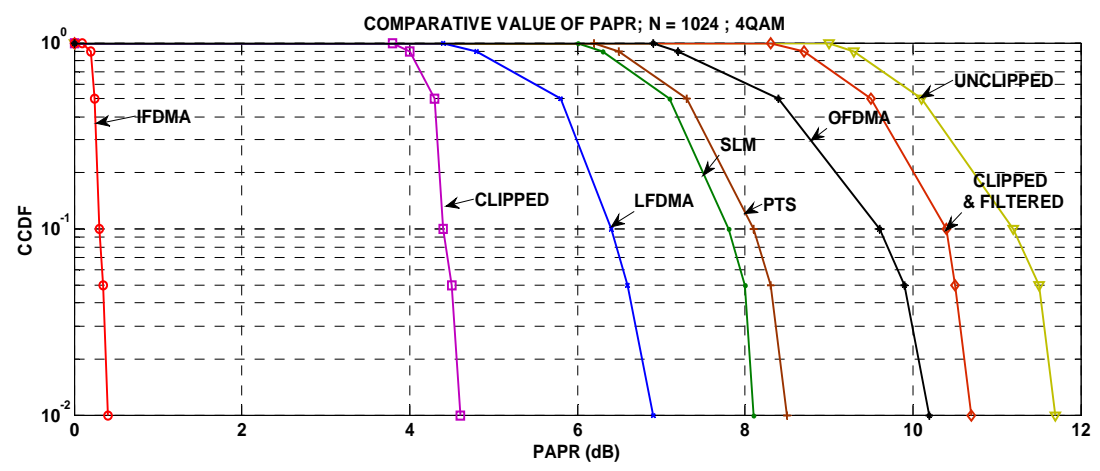

Figure 17. Comparative value of PAPR with different reduction techniques for $\mathrm{N}=1024$

Reduction in PAPR value of 11.3, 3.5, 3.4 and $1.0 \mathrm{~dB}$ have been obtained with DFT-spread (IFDMA), SLM, PTS and CF techniques respectively. It can be observed form figure that IFDMA gives the lowest PAPR of $0.4 \mathrm{~dB}$ obtained so far in the literaure at the cost of marginal implementation complexity. Clipping and filtering method is the simplest technique from implementation point of view but results in spectral regrowth and degradation in BER value. SLM has better performance than PTS at the cost of computational complexity. Use of particular reduction technique depends upon the nature of application and system complexity involved.

\section{CONCLUSION}

Even though OFDM is one of the spectral efficient modulation technique for next generation high data rate communication systems, it degrades the linearity of power amplifiers as it suffers from high value of PAPR. High PAPR causes power amplifiers to operate in the nonlinear region. Many techniques are used for PAPR reduction. In this paper, we have investigated four different PAPR reduction techniques: clipping and filtering, selective mapping method, partial transmit sequence and DFT- spread technique. The PAPR value obtained at $0.01 \%$ of CCDF for 1024 number of sub carriers without applying any reduction technique is $11.7 \mathrm{~dB}$. On application of reduction techniques value of PAPR has been reduced significantly. The observed PAPR values with DFT-spread (IFDMA), SLM, PTS and CF techniques are 0.4, 8.2, 8.3 and $10.7 \mathrm{~dB}$ respectively. Significant reduction of $11.3,3.5,3.4$ and $1.0 \mathrm{~dB}$ have been obtained with DFT-spread (IFDMA), SLM, PTS and CF techniques respectively. Use of a particular reduction technique depends upon the nature of application and system complexity involved.

\section{REFERENCES}

[1] Park D. H. and Song H. K., "A New PAPR Reduction Technique of OFDM System with Nonlinear High Power Amplifier," IEEE Transactions on Consumer Electronics, vol/issue: 53(2), pp. 327-332, 2007.

[2] Han S. H. and Lee J. H., "An Overview of Peak-To-Average Power Ratio Reduction Techniques for Multicarrier Transmission," IEEE Wireless Communications, vol/issue: 12(2), pp. 56- 65, 2006.

[3] Proakis J. G., "Digital Communications," McGraw-Hill, New York, USA, 2000.

[4] Nee R. V. and Prasad R., "OFDM for Wireless Multimedia Communications," Artech House Publishers, Norwood, MA, USA, 2000.

[5] Prasad R., "OFDM for Wireless Communications Systems," Artech House Publishers, Norwood, MA, USA, 2004.

[6] Hara S. and Prasad R., "Multicarrier Techniques For 4G Mobile Communications," Artech House Publishers, Norwood, MA, USA, 2003.

[7] Cho Y. S., et al., "MIMO- OFDM Wireless Communications with Matlab," IEEE Press, John Wiley and Sons (Asia) Pvt. Ltd., 2010. 
[8] Wang L. and Tellambura C., "A Simplified Clipping and Filtering Technique for PAR Reduction in OFDM Systems," IEEE Signal Processing Letters, vol/issue: 12(6), pp. 453-456, 2005.

[9] Armstrong J., "Peak-to-average power reduction for OFDM by repeated clipping and frequency domain filtering," Electronics Letters, vol/issue: 38(5), pp. 246-247, 2002.

[10] Li X. and Cimini L. J., "Effects of Clipping and Filtering on the Performance of OFDM," IEEE Communications Letters, vol/issue: 2(5), pp. 131-133, 1998.

[11] Zhu X., et al., "Simplified Approach to Optimized Iterative Clipping and Filtering for PAPR Reduction of OFDM Signals," IEEE Transactions on Communications, vol/issue: 61(5), pp. 1891-1901, 2013.

[12] Zhu X., et al., "Descendent clipping and filtering for cubic metric reduction in OFDM systems," Electronics Letters, vol/issue: 49(9), pp. 599-600, 2013.

[13] Wang Y. C. and Luo Z. Q., "Optimized Iterative Clipping and Filtering for PAPR Reduction of OFDM Signals," IEEE Transactions on Communications, vol/issue: 59(1), pp. 33-37, 2011.

[14] Deng S. K. and Lin M. C., "Recursive Clipping and Filtering with Bounded Distortion for PAPR Reduction," IEEE Transactions on Communications, vol/issue: 55(1), pp. 227-230, 2007.

[15] Ryu H. G., et al., "PAPR Reduction Using Soft Clipping and ACI Rejection in OFDM System," IEEE Transactions on Consumer Electronics, vol/issue: 48(1), pp. 17-22, 2002.

[16] Bguml R. W., et al., "Reducing the peak-to-average power ratio of multicarrier modulation by selected mapping," Electronics Letters, vol/issue: 32(22), pp. 2056-2057, 1996.

[17] Wang C. L., et al., "A Low-Complexity PAPR estimation Scheme for OFDM and Its Application to SLM-Based PAPR Reduction,” IEEE Journal of Selected Topics in Signal Processing, vol/issue: 4(3), pp. 637- 645, 2010.

[18] Goff S., et al., "A Novel Selected Mapping Technique for PAPR Reduction in OFDM Systems," IEEE Transactions on Communications, vol/issue: 56(11), pp. 1775- 1779, 2008.

[19] Cimini L. J. and Sollenberger N. R., "Peak-to-Average Power Ratio Reduction of an OFDM Signal Using Partial Transmit Sequences," IEEE Communications Letters, vol/issue: 4(3), pp. 86-88, 2000.

[20] Varahram P. and Ali B. M., "Partial Transmit Sequence Scheme with New Phase Sequence for PAPR Reduction in OFDM Systems,” IEEE Transactions on Consumer Electronics, vol/issue: 57(2), pp. 366-371, 2011.

[21] Baxley R. J. and Zhou G. T., "Comparing Selected Mapping and Partial Transmit Sequence for PAR Reduction," IEEE Transactions on Broadcasting, vol/issue: 53(4), pp. 797- 803, 2007.

[22] Myung H. G., et al., "Single Carrier FDMA for Uplink Wireless Transmission," IEEE Vehicular Technology Magazine, vol/issue: 1(3), pp. 30-38, 2006.

[23] Lin Z., et al., "Analysis of Receiver Algorithms for LTE SC-FDMA Based Uplink MIMO Systems," IEEE Transactions on Wireless Communications, vol/issue: 9(1), pp. 60-65, 2010.

[24] Hasegawa F., et al., "A Novel PAPR Reduction Scheme for SC-OFDM with Frequency Domain Multiplexed Pilots," IEEE Communications Letters, vol/issue: 16(9), pp. 1345-1347, 2012.

[25] Berardinelli G., et al., "OFDMA vs. SC-FDMA: Performance Comparison in Local Area IMT-A Scenarios," IEEE Wireless Communications, vol/issue: 15(5), pp. 64-72, 2008.

\section{BIOGRAPHIES OF AUTHORS}

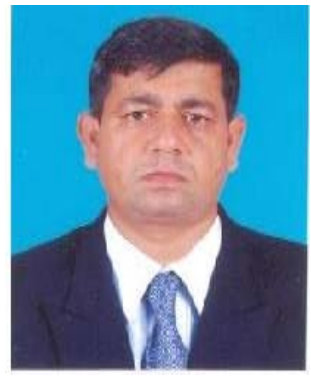

Shatrughna Prasad Yadav received B. Tech. (AMIE) degree in electronics and communication engineering from the Institution of Engineers (India) in 1992, MBA in marketing management from Indira Gandhi National Open University, New Delhi in 1998, M. Tech. in digital systems from Motilal Nehru National Institute of Technology, Allahabad in 2002. He is currently pursuing Ph.D. in Electronics and Communication Engineering from Gujarat Technological University, Ahmedabad. From 1986 to 2006, he was with Indian Air force. From 2006 to 2007, he worked as senior lecturer in electronics and communication engineering department at Institute of Technology, Nirma University, Ahmedabad. Since 2007, he is with the Institute of Technology and Engineering, Indus University, Ahmedabad as a head of Electrical and Electronics Engineering department. His research interest includes digital communication systems, electromagnetics, microwave and digital signal processing.

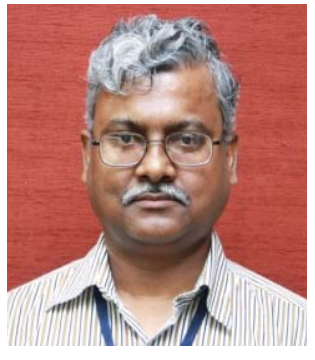

Subhash Chandra Bera received the B.Sc. degree (with honors) in physics from Presidency College, Calcutta, B. Tech. and M. Tech. degrees in radio physics and electronics from the Institute of Radio Physics and Electronics, University of Calcutta, and Ph.D. degree in Microwave Engineering from Gujarat University. Since 1994, he is with the Space Applications Centre, (ISRO), India, where he has been involved in design and development of various microwave active subsystems that are being used in many communication and navigation payload projects such as the INSAT-2, INSAT-3, INSAT-4 and GSAT of spacecraft. Presently, he is serving as head of the Satcom and navigation Systems engineering Division, Space Applications Centre, ISRO. He is Ph.D. research supervisor of Nirma University and Gujarat Technological University (GTU) in the field of Electronics and communication engineering. 